\title{
Efficiency of the Glycolytic Pathway in Erythrocytes of Children with Down's Syndrome
}

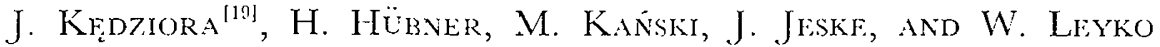 \\ Department of General and Physiological Chemistry, Department of Histology, and I Clinic of Pediatrics, Academy of Medicine, and \\ Department of Biophysics, University of Lodz, Lodz, Poland
}

\section{Extract}

The intermediates of the glycolytic pathway were investigated in erythrocytes of children with Down's syndrome and the results achieved were compared with those obtained from healthy children of the same age. In the acid-soluble fraction obtained from the erythrocytes, the levels of the intermediates of the glycolytic pathway were determined. The adenine and guanine nucleotides, coenzymes, and inorganic phosphate $(\mathrm{Pi})$ and some other intermediates were examined. The adenine nucleotides: adenosine 5'-monophosphate (AMP), adenosine 5'-diphosphate (ADP), adenosine $5^{\prime}$-triphosphate (A'P) and the guanine nucleotide: guanosine $5^{\prime}$-triphosphate (GTP) were determined. The nicotinamide adenine dinucleotide $(\mathrm{NAI})$ ) and nicotinamide adenine dinucleotide phosphate (NADP), two glycolytic pathway coenzymes, were examined. Hexose diphosphate (HI)P) and 2,3-diphosphoglyceric acid (2,3-I)PG) were tested.

'Three groups were distinguished after the determination of the karyotype in the children examined: group $I$, seven children with Down's syndrome and trisomy ( $)$ (karyotype 47,XX,G+ or 47,XY,G+); group II, two children (siblings) with Down's syndrome and $\mathrm{G} / \mathrm{G}$ translocation (karyotype $46, \mathrm{XX}, \mathrm{G}-\mathrm{t}(\mathrm{GqGq})+$ mat or $46, \mathrm{XY}$, $\mathrm{G}-\mathrm{t}\left(\mathrm{GqG}_{\mathrm{q}}\right)+$ mat $)$; and group III, healthy children with a nomal karyotype, corresponding to the sex. The results of the biochemical investigations in all of the three groups were compared.

'Iaking the values obtained for the healthy children as standard, a considerable decrease in the levels of ATP and 2,3-I)PG and an increase in the levels of AMP, GTP, $N A I$ ), NADP, Pi, and HIP were noticed in the group of children with Down's syndrome and trisomy G. 'Ihe ADP concentration was the same as in the control group. The values of some intermediates obtained for the group of mongols with unbalanced translocation $G / G$ were approximately the same as the values obtained for the group of mongols with trisomy G. "The 2,3-DPG level was just as low as in the mongol group with trisomy $\mathrm{G}$.

The results of the calculations, developed by means of the Student test, are statistically significant.

\section{Speculation}

The levels of the glycolytic pathway intermediates in erythrocytes of children with Down's syndrome deviate from normal. The differences which were observed may reflect disturbances of enzymatic activity. It is also possible that these differences are a 
result of nutritional disturbances or are caused by the incidence of a population of atypical erythrocytes.

\section{Introduction}

Two kinds of karyotype aberration have becn described in Down's syndrome [11]. Trisomy $G$ is most frequently found, whereas translocation is found less frequently. The object of investigation of many authors has been the interdependence between chromosomal anomalies and the changes in metabolism $[1,2,3$, $6,7,14,15]$. In children with trisomy $G$, an increased activity of creatine phosphokinase [15], cholinesterase [1] and enolase [1] has been observed in serum. In crythrocytes, an increased activity of galactose-1-phosphate uridyl transferase [3, 10], a threefold increase of glucose-6-phosphate dehydrogenase activity [7, 14], and a $50 \%$ rise of phosphohexokinase [1] have been observed. Baikie et al. [1] have demonstrated that the concentration of adenosine 5 -triphosphate (ATP) is slightly reduced in erythrocytes.

Rosner et al. [14] state that the increase in glucose6-phosphate dehydrogenase activity has not been observed in children with unbalanced chromosomal translocation.

This increase in the glucose-6-phosphate dehydrogenase activity seems to be a characteristic enzymatic clisturbance in the erythrocytes of children with Down's syndrome and trisomy $G$ in the karyotype. One can assume that, in children with trisomy $G$, the Embden-Meyerhof-Parnas glycolytic pathway beginning with glucose-6-phosphate may not function normally. This may lead to a clecrease in the production of ATP. The sole source of ATP in erythrocytes is anaerobic glycolysis. This problem seemed interesting enough to warrant investigations on the determination of A'TP and of the intermediates and coenzymes of the glycolytic pathway.

\section{Materials and Methods}

Fifteen children, nine with Down's syndrome, were examined. The karyotype was determined in all the patients. For this purpose, lymphocytes of the peripheral blood were cultured according to the method given by Moorhead et al. [9]. In the mongol group, trisomy $G$ was found in seven children, and in two, brother and sister, unbalanced $G / G$ translocation was found. The mother and younger sister of the two with the unbalanced $G / G$ translocation have a balanced
Table $I$. Results of cytogenetic investigations

\begin{tabular}{|c|c|c|c|c|c|}
\hline Group & No. & $\begin{array}{c}\text { Child } \\
\text { investigated }\end{array}$ & $\begin{array}{l}\text { Age, } \\
\text { yr }\end{array}$ & Sex & Karyotype \\
\hline \multirow[t]{7}{*}{$I$} & 1 & HO & 17 & $F$ & $47, X \times, G+$ \\
\hline & 2 & $B M$ & 16 & $F$ & $47, X X, G+$ \\
\hline & 3 & $S C$ & 16 & $F$ & $47, X X, G+$ \\
\hline & 4 & $M(D)$ & 16 & $F$ & $47, X X, G+$ \\
\hline & 5 & $J P$ & 11 & $\mathrm{M}$ & $47, X Y, G+$ \\
\hline & 6 & $B F$ & 13 & $\mathrm{M}$ & $47, \mathrm{XY}^{r}, \mathrm{G}+$ \\
\hline & 7 & $J L$ & 14 & $\mathrm{M}$ & $47, \mathrm{XY}, \mathrm{G}+$ \\
\hline \multirow[t]{2}{*}{ II } & 8 & $E K^{1}$ & 16 & $\mathrm{~F}$ & $\begin{array}{l}46, \mathrm{XX}, \mathrm{G}-\mathrm{t}(\mathrm{GqGq}) \\
+ \text { that }\end{array}$ \\
\hline & 9 & $J K^{l}$ & 18 & $\mathrm{M}$ & $\begin{array}{l}\text { 46, } \mathrm{XY}, \mathrm{G}-, \mathrm{t}(\mathrm{GqGq}) \\
\quad-\text { - } 1 \text { at }\end{array}$ \\
\hline \multirow[t]{6}{*}{$I I I$} & 10 & $I V K$ & 14 & li & $46, \times x$ \\
\hline & 11 & $P G$ & 15 & M & $46, X Y$ \\
\hline & 12 & $K K$ & 18 & $\mathrm{M}$ & $46, X Y$ \\
\hline & 13 & $k K$ & 15 & $M$ & $46, X Y$ \\
\hline & 14 & $Z L$ & 13 & $\mathrm{~F}$ & $46, \times \times$ \\
\hline & 15 & IV'S & 14 & $M$ & $46, X Y$ \\
\hline
\end{tabular}

Brother and sister.

translocation, karyotype $45, \mathrm{XX}, \mathrm{G}-\mathrm{G}-\mathrm{t}(\mathrm{GqGq})+$. On the basis of this study, unbalanced 21 i 22 translocation was diagnosed in patients examined by the authors. The control group consisted of six healthy chilclren whose karyotype was normal. In all of the children examined, blood morphology and hematocrit value were determined. The amount of nucleotides and coenzymes was closely related to the hematocrit values determined previously. All of the patients examined were Caucasian. On the basis of the analysis of the karyotype, the patients were divided into three groups: group I, seven children with Down's syndrome and trisomy $G$ in the karyotype; group II. two children with Down's syndrome and unbalanced 2l/22 translocation in the karyotype; and group $I H$, six chilclren with a normal karyotype. The children in groups $I$ and $I I$ did not have any other ailment apart from Down's syndrome symptoms. The caloric nutritional value was approximately the same as in the control group. The sex, age, and other information concerning the patients are presented in Table I. A total of 600 tests was performed.

Heparinized venous blood, $11 \mathrm{ml}$, was collected from cach patient for the purpose of carrying out biochemi- 
cal investigations. The blood was collected at a given time when the patient was fasting. Addlitionally, the sedimentation rate was determined and the hematocrit was found twice on a high-speed hematocrit centrifuge [17]. The blood was stored for $1 \mathrm{hr}$ at a temperature of $+1^{\circ}$ until the beginning of the true biochemical investigations in the nongol group and in the control group. Next, the total erythrocyte mass was obtained from $10 \mathrm{ml}$ of the blood by centrifugation in a refrigerated centrifuge [18].

The methods for the isolation of the erythrocytes and the technique for obtaining the acid-soluble fraction have been given in a previous article by the authors [6]. If traces of hemolysis of the blood were observed, the test was discarded. The compounds contained in the acicl-soluble extract from the erythrocytes were separated by the method of Hurlbert et al. [t].

\section{Results}

The chromosomal analysis of children with Down's syndrome demonstrated trisomy $G$ in seven and unbalanced $G / G$ translocation, "centric fusion type," in two (siblings). The chromosomal aberration aftected all of the cells investigated and no anomalies were lound in the remaining chromosomes. The sex chromosomes correspond to the phenotype sex.

The karyotype of the healthy children was normal. The results of the cytogenetic tests are given in Table I. 'The blood morphology of the children with Down's synclrome did not differ greatly from the morphology of the control group. In particular, reticulocytosis was not observed in any of those investigated.

The following fractions were separated from the acid-soluble extract obtained from the exythrocytes of the children investigated: adenosine 5'-monophosphate (AMP), adenosine 5' -diphosphate (ADP), adenosine 5'triphosphate (ATP), guanosine $5^{\prime}$-triphosphate (GTP), nicotinamide adenine dinucleotide (NAD), nicotinamicle adenine clinucleotide phosphate (NADP), inorganic phosphate $(\mathrm{Pi})$, hexose diphosphate (IDDP) and 2,3-diphosphoglyceric acid (2,3-DPG).

Moreover, taking into consideration the known order of clution of the investigated compounds in this chromatographic system, peaks $A$ and $D$ were identified as cytidine derivatives, and peak $I$ was identified as uridine diphosphoglucose (UDPG). The results obtained for the children with Down's syndrome are given in Table II and for the healthy children in Iable III. Table IV presents clata for the children with unbalanced $\mathrm{C} / \mathrm{G}$ translocation (siblings). The arerage values of phosphate esters in erythrocytes of mongols with trisomy $G$, of those with unbalanced $\mathrm{G} / \mathrm{G}$ translocation. and of the healthy children are given in Table $V$.

Figure I depicts the chromatographic distribution of the phosphate esters isolated from erythrocytes of children with Down's syndrome and trisomy $G$. Figure 2 represents the amounts of the compounds in mongols with unbalanced $\mathrm{G} / \mathrm{G}$ translocation. The results obtained from the control group of children of the same age and sex are given in Figure 3.

\section{Discussion}

When the nucleoticle and coenzyme contents of the acid-soluble fraction obtained from erythrocytes of children with trisomy $\mathrm{G}$ are compared with those of

Table II. Components of the glycolytic pathway found in erythrocytes of children with Down's syndrome (trisomy G). ${ }^{1}$ Values expressed as micromoles per $100 \mathrm{ml}$ elythrocytes

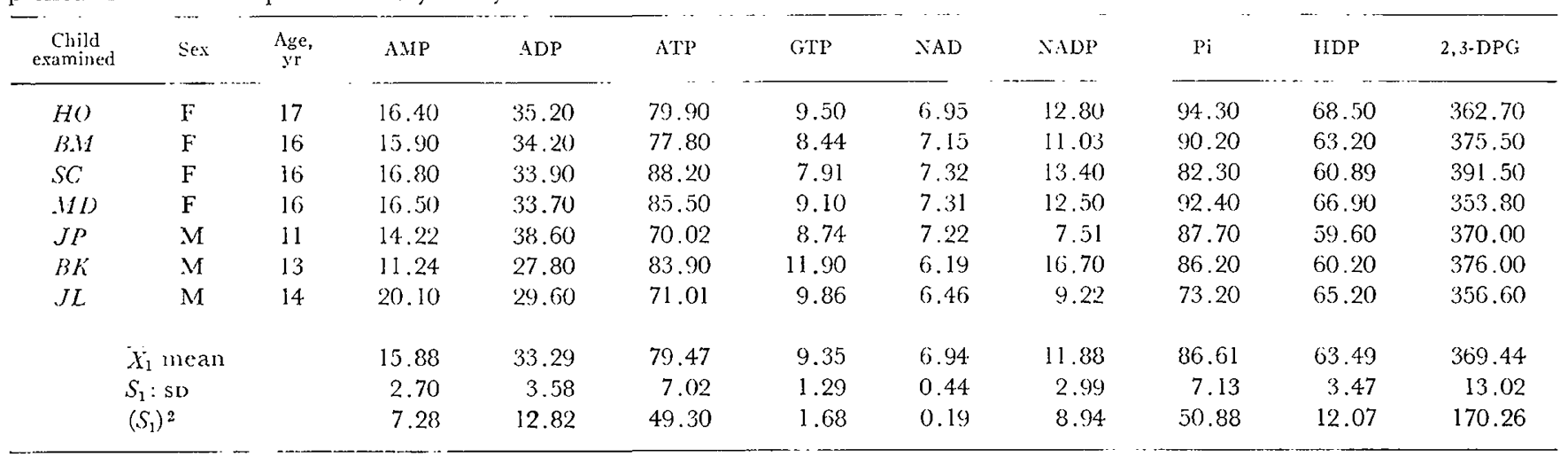

1 AMP : adenosine 5'-monophosphate; ADP: adenosine 5'-diphosphate; ATP: adenosine 5'-triphosphate; GTP: guanosine $5^{\prime}$-triphosphate; NAD : nicotinamide adenine dinucleotide; NADP: nicotinamide adenine dinucleotide phosphate; Pi: inorganic phosphate; HDP: hexose diphosphate; 2,3-IPG : 2,3-diphosphoglyceric acid. 
Table III. Components of the glycolytic pathway found in erythrocytes of control group of children. ${ }^{1}$ Values expressed as micromoles per $100 \mathrm{ml}$ ery throcytes

\begin{tabular}{|c|c|c|c|c|c|c|c|c|c|c|c|}
\hline $\begin{array}{c}\text { Child } \\
\text { examined }\end{array}$ & Sex & $\begin{array}{c}\text { Age, } \\
\text { yr }\end{array}$ & AMIP & ADP & ATP & GTP & $\therefore A D$ & $\therefore A D P$ & $\mathrm{Pi}_{\mathrm{i}}$ & HDP & $2,3-\mathrm{DPG}$ \\
\hline$I W K$ & $\mathrm{~F}$ & 14 & 7.80 & 32.60 & 116.40 & 5.30 & 6.60 & 9.50 & 47.70 & 48.10 & 621.30 \\
\hline$P G$ & $\mathrm{M}$ & 15 & 4.70 & 44.70 & 135.00 & 5.80 & 5.10 & 8.90 & 76.40 & 52.00 & 780.00 \\
\hline$K K$ & $\mathrm{M}$ & 18 & 4.80 & 37.10 & 169.20 & 7.70 & 3.80 & 8.30 & 43.70 & 61.00 & 835.00 \\
\hline$K K$ & $\mathrm{M}$ & 15 & 6.50 & 35.80 & 83.20 & 6.60 & 3.60 & 7.10 & 78.20 & 47.40 & 821.00 \\
\hline$Z L$ & $\mathrm{~F}$ & 13 & 7.10 & 38.60 & 118.10 & 5.40 & 2.70 & 6.90 & 70.20 & 40.60 & 650.50 \\
\hline$W S$ & $\mathrm{M}$ & 14 & 6.90 & 42.20 & 176.10 & 7.90 & 3.82 & 9.20 & 50.40 & 47.30 & 690.10 \\
\hline \multirow{2}{*}{\multicolumn{3}{|c|}{$\begin{array}{l}\bar{X}_{:} \text {mean } \\
S_{2}: \mathrm{SD} \\
\left(S_{2}\right)^{2}\end{array}$}} & 1.21 & 4.38 & 38.06 & 1.143 & 1.37 & 1.09 & 15.53 & 6.76 & ()1.03 \\
\hline & & & 1.47 & 19.24 & 1449.13 & 1.307 & 1.89 & 1.20 & 241.22 & 45.77 & 8297.99 \\
\hline
\end{tabular}

1 AMP: adenosine 5'-monophosphate; ADP: adenosine 5'-diphosphate; ATP: adenosine 5'-triphosphate; GTP: guanosine 5'-triphosphate; $\mathrm{N} \backslash \mathrm{D}$ : nicotinamide adenine dinucleotide; NNDP: nicotinamide adenine dinucleotide phosphate; Pi: inorganic phosphate; HDP: hexosc diphosphate; 2,3-DPG : 2,3-diphosphoglyccric acid.

Table IV. Components of the glycolytic pathway found in erythrocytes of children with Down's syndrome (unbalanced G/G translocation ). ${ }^{1}$ Values expressed as micromoles per $100 \mathrm{ml}$ erythrocytes

\begin{tabular}{|c|c|c|c|c|c|c|c|c|c|c|c|}
\hline $\begin{array}{c}\text { Child } \\
\text { examined }\end{array}$ & Sex & $\underset{\text { yr }}{\text { Age, }}$ & A.MP & $\mathrm{ADP}$ & $\mathrm{A}^{\prime} \mathrm{TP}$ & GTP & $\mathrm{AAD}$ & NAIDP & $\mathrm{Pi}_{\mathrm{i}}$ & HDP & $2,3-\mathrm{DPG}$ \\
\hline$E K$ & $\mathrm{~F}$ & 16 & 10.80 & 36.10 & 111.20 & 7.50 & 6.90 & 9.31 & 77.20 & 60.40 & 388.50 \\
\hline$J K^{\prime}$ & $\mathrm{M}$ & 18 & 9.10 & 35.40 & 117.40 & 6.80 & 6.10 & 8.83 & 68.30 & 55.40 & 401.70 \\
\hline \multicolumn{2}{|c|}{ Mean } & & 9.95 & 35.75 & 114.30 & 7.15 & 6.50 & 9.07 & 72.75 & 57.90 & 305.10 \\
\hline
\end{tabular}

1 . MP: adenosine 5'-monophosphate; ADP: adenosine 5'-diphosphate; XIP : adenosine 5'-triphosphate; GrP : guanosine 5'-triphosphate; NAD: nicotinamide adenine dinucleotide; NADP: nicotinanide adenine dinucleotide phosphate; Pi: inorganic phosphate; HDP: hexose diphosphate; 2,3-DPG: 2,3-diphosphoglyceric acid.

Table $V$. Average values of components of the glycolytic pathway found in erythrocytes. ${ }^{1}$ Values expressed as micromoles per 100 ml of erythrocytes

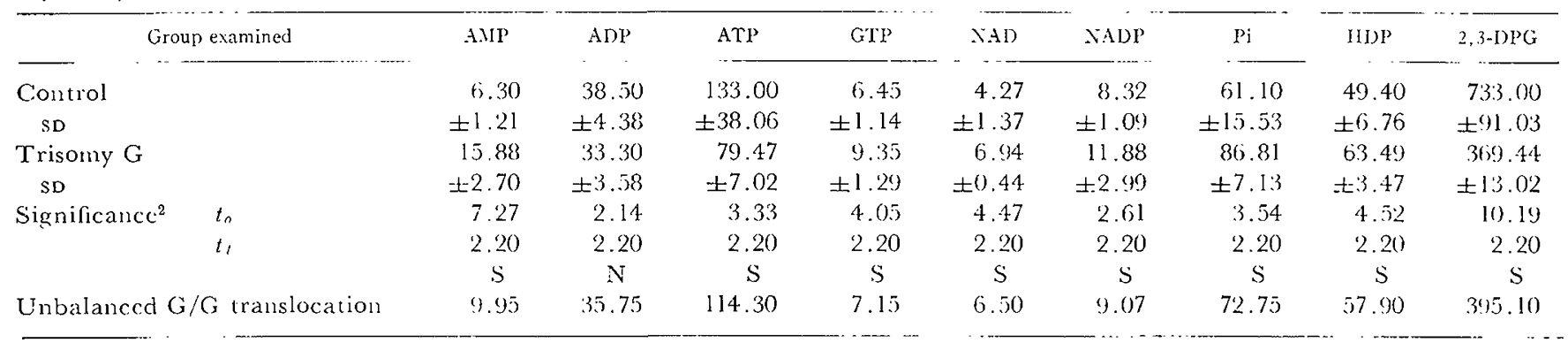

1 AMP: adenosine 5'-monophosphate; . IDP: adenosine 5'-diphosphate; ATP: adenosine 5'-triphosphate; GTP: guanosine 5'-triphosphate; NAD: nicotinamide adenine dinucleotide; N:\DP: nicotinamide adenine dinucleotide phosphate; Pi: inorganic phosphate; HDP: hexose diphosphate; 2,3-DPG : 2,3-diphosphoglyceric acid.

${ }^{2}$ Significant differences between control group and trisomy $G$ group (nongols) are indicated when $P<0.05$. S: significant; $N$ : not significant; $t_{0}: t$ calculated; $t_{t}: t$ table.

the control group, several differences may be observed.

Special attention should be drawn to a considerable fall of the ATP content, which amounted to about half its normal value $[12,13,16]$. The 2,3-DPG content also decreased by about $50 \%$; on the other hand, the content of HDP rose. Morcover, a characteristic increase in the amounts of the coenzymes $\mathrm{NAD}$ and
NADP as well as Pi was observed. Of the adenine nucleotides, only the ADP content dicl not show any change, whereas the amount of AMP increased twofold. The guanine nucleoticle concentration was also higher than in the control group.

In a mature human erythrocyte, there are only two pathways of glucose metabolism: anacrobic glycolysis 


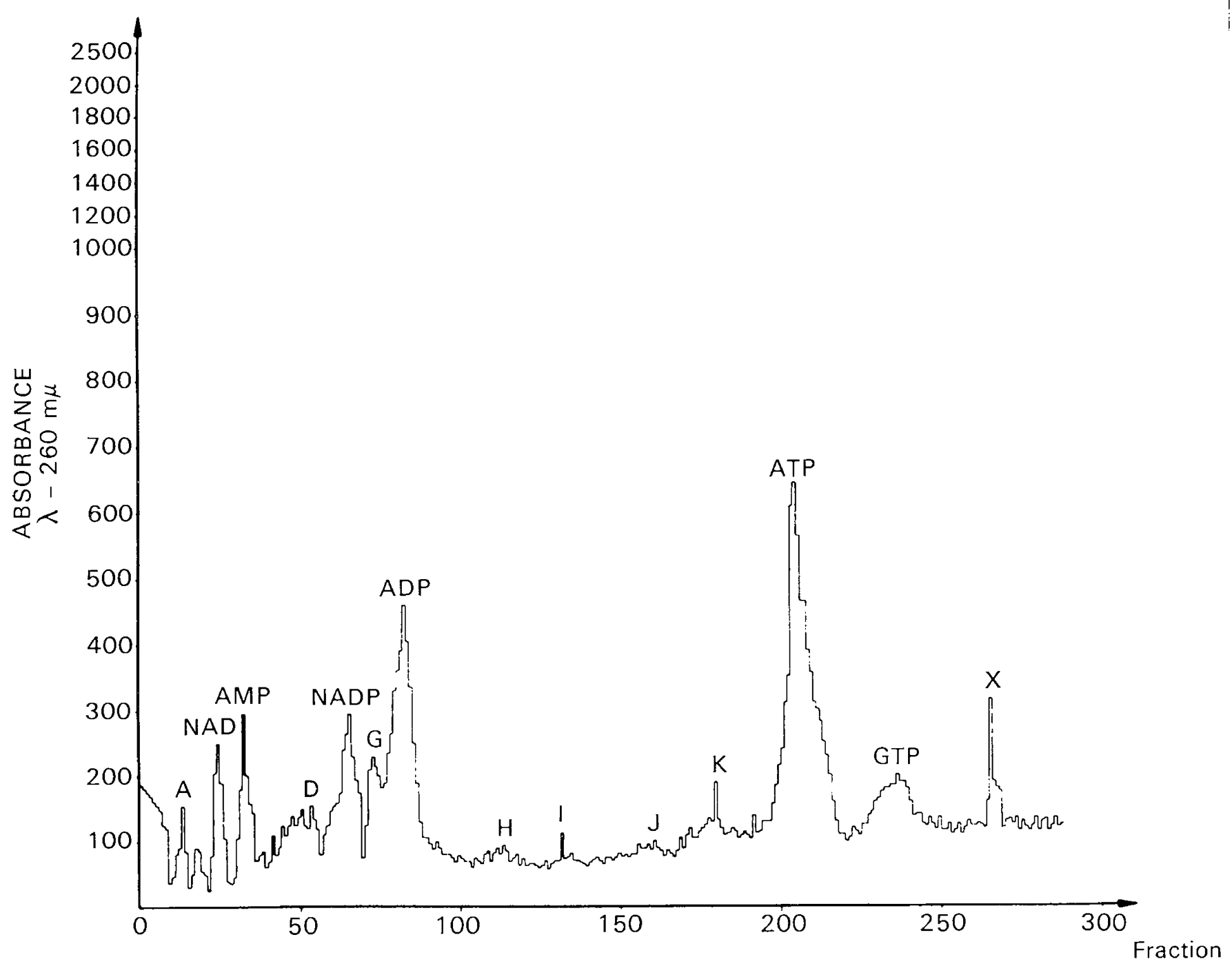

Fig. 1. The chromatographic distribution of the phosphate esters isolated from erythrocytes of children with Down's syndrome and trisomy G. Results represent 600 determinations.

and the pentose cycle [8]. Because of this, the red cell is a suitable model for investigating glucose metabolism disturbances. Both of these carbohydrate pathways are necessary for the process of ATP synthesis.

Our investigations are not concerned with the direct determination of enzyme activity, but with the quantitative changes in concentrations of nucleotides and intermediates. These changes permit the indirect evaluation of enzyme activity. The results of our investigations may suggest two kinds of mechanisms which disturb the synthesis of ATP.

The first mechanism depends upon disturbances of the pentose cycle. The investigations of Rosner et al. [14] have shown that, in children with trisomy $G$, the glucose-6-phosphate dehydrogenase activity is consider- ably increased. The rise in the concentration of NADP, the coenzyme of this dehydrogenase, has been demonstrated in our experiments. This observation is in agreement with the results of Rosner et al. [14] and it secms to confirm the possibility of an increased production of 6-phosphogluconic acid. This would suggest an increased turnover of the pentose cycle in children with trisomy G.

The second possible mechanism which would explain the decrease of the ATP content would be partial inactivation of the enzymes. Our unfinished investigations on the activity of the enzymes of the discussed pathway do not permit the precise location of the disturbance which may concern the dehydrogenase of glyceraldehyde-3-phosphate. 


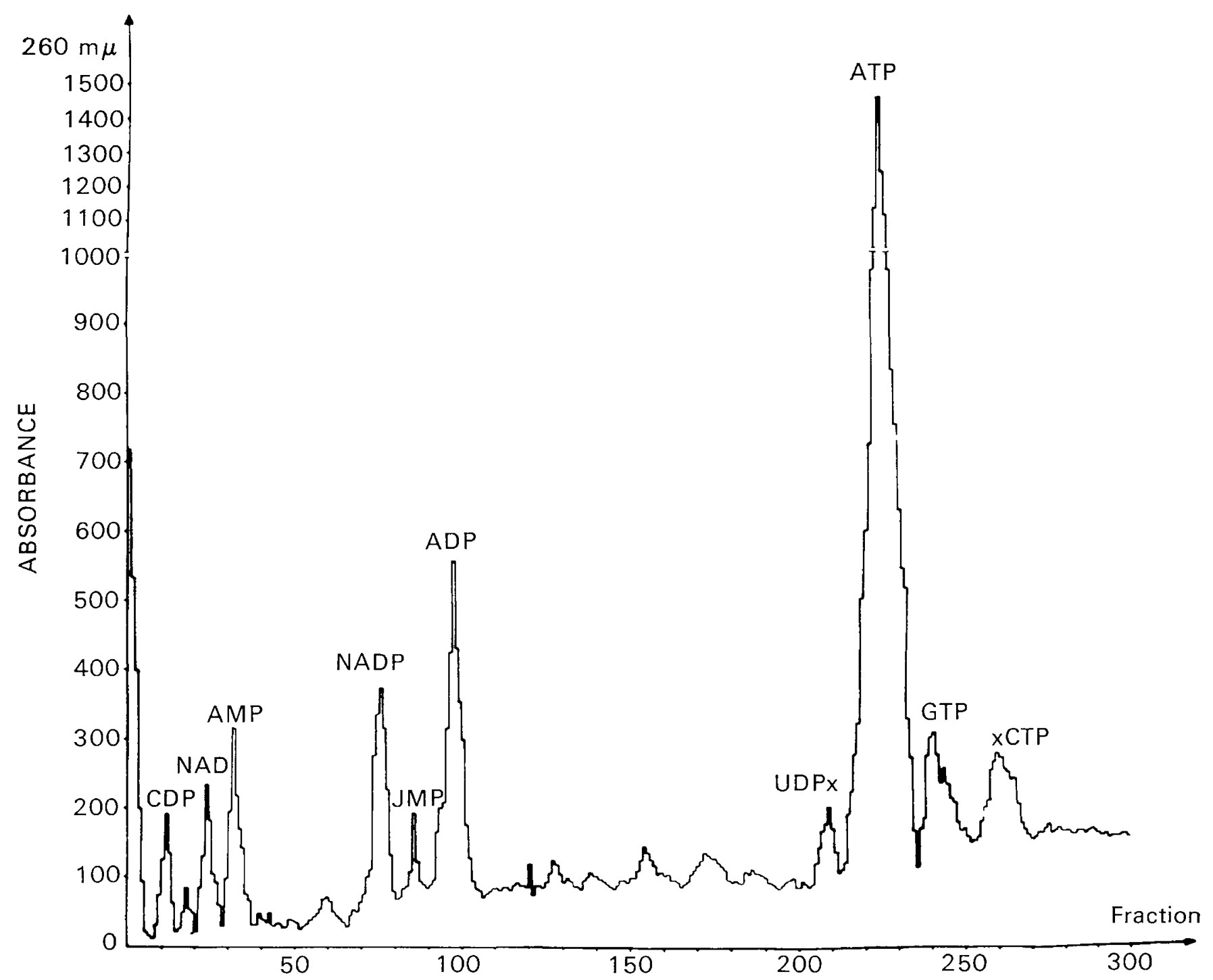

IFig. 2. The chromatographic distribution of the phosphate esters isolated from erythrocytes of children with Down's syndrome and unbalanced $\mathrm{G} / \mathrm{G}$ translocation.

The ATP synthesis in Down's syndrome with unbalanced $G / G$ translocation was normal in the cases investigated. This is in agreement with the results of Rosner et al. [14], who did not observe any increased activity of glucose-6-phosphate dehydrogenase in mongoloid children with unbalanced translocations.

A genetic interpretation of the biochemical disturbances in children with Down's syndrome is difficult. The results of our investigations and the communications of other scientists $[14,15]$ show that there are biochemical differences between patients with trisomy $G$ and those with unbalanced chromosomal translocation. Finding these biochemical differences in the face of the great similarity of the phenotype [11] is a further difficulty in giving the genetic interpretation. It does not seem possible to explain the biochemical differences by a slight loss of genetic material when the centric fusion type of translocation takes place.

The biochemical anomalies observed in the patients with trisomy $G$ may be explained by the interference with genetic balance, especially the induction and repression processes $[2,5]$. Consiclering the results of the authors' investigations, it can only be said that the gene loci affect the regularity of the course of glycolysis in the erythrocytes of children with unbalanced $G / G$ 


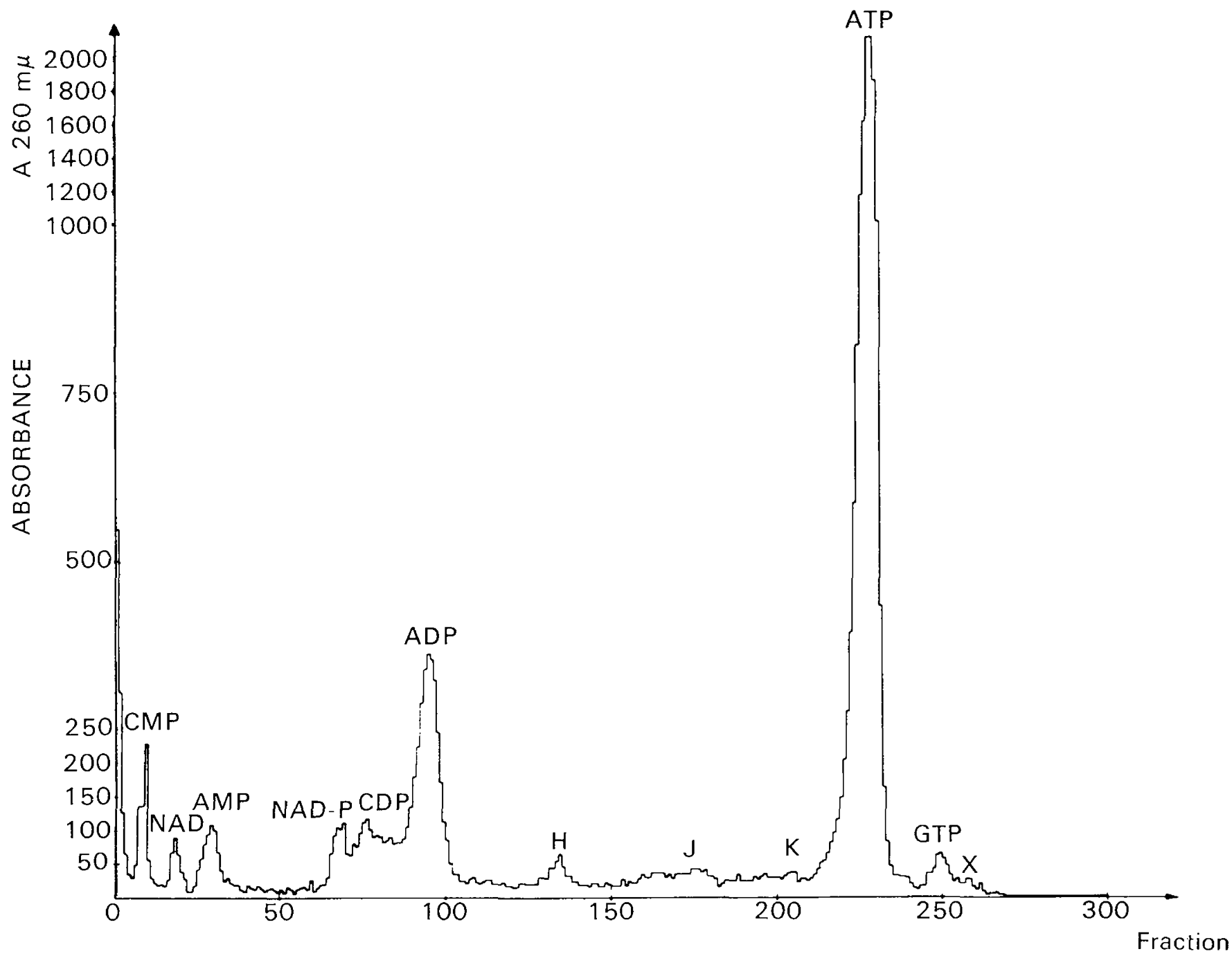

Fig. 3. The chromatographic distribution of the phosphate esters isolated from erythrocytes of children of the same age and sex in the control group.

translocation to the same degree as in healthy children. In patients with trisomy $G$, the genetic regulation of this process is disturbed.

\section{Summary}

Applying the continuous gradient column chromatography method, some intermediates of the glycolytic pathway in acid-soluble extracts of erythrocytes from children with Down's syndrome were isolated and determined.

In children with trisomy $G$, as compared with the control group, a marked clecrease in ATP, the 2,3DPG content, and higher concentrations of AMP, GTP, NAD, NADP, Pi, and HDP were noticed. The concentration of ADP was the same as in the control group. In the siblings with unbalanced $G / G$ translocation, a slight decrease in the ATP content was observed, and the 2,3-DPG level was just as low as in the mongoloid children with trisomy $\mathrm{G}$.

\section{References and Notes}

I. Bukme, A. G., Loder, B. P., De Grouchx, G. C., AND Pitt, D. B.: Phosphohexokinase activity of erythrocytes in Mongolism. Lancet, $i$ : 412 (1965).

2. Grumbach, M. M., Marks, P. $\Lambda$., and Morishima, A.: Erythrocyte glucose-6-phosphate dehydrogenase activity and $\mathrm{X}$ chromosome polysomy. Lancet, $i$ : 1330 (1962).

3. IIsra, D. Y. Y., INouYe, T., WoNG, P., AND SOUTH, A.: Studies on galactose oxidation in Down's syndrome. New Engl. J. Med., 270: 1085 (1964). 
4. Hurlbert, R. B., Schmitz, H., Bruma, A. F., and Pottre, V. R.: Nucleotide metabolism. II. Chromatographic separation of acid-soluble nucleotides. J. Biol. Chem., 209: 23 (1954).

5. JACOB, I., AND MONOD, J.: Genelic regulatory mechanisms in the synthesis of proteins. J. Mol. Biol., 3: 318 (196I).

6. KaÁSKI, M., KF̨DZIORA, J., AND Hë̈Nir, H.: Investigations upon the content of some phosphate esters in acid-solulble extracts of erythrocytes from children with Down's syndrome (preliminary communication) (In Polish). Biul. W. A. M., 10: $147(1967)$.

7. IING-YC-SHIH, WONG, P., AND INOLYe, 'T.: Finzymes in Down's syndrome. I.ancet, ii: 747 (1965).

8. Minakimi, S., Suzuke, C., A.jo Yoshikawa, H.: Studies on erythrocyte glycolysis. IV. Kinetics of $P^{332}$ incorporation into 2,3-diphosphoglycerate and A'TP. J. Biochem. (Tokyo), 60: 707 (1966).

9. Moorhead, P. S., Noweld, P. C., Mrildman, W. J., Bartips, D. M., .ND Hoxgerford, D. A.: Chromosome preparations of leukocytes from human peripheral blood. Exp. Cell Res., 20: 613 (1960).

10. NG, W. G., Brkgrr., W. R., AND DonNel, G. N.: Galactose-1phosphate uridyl-transfcrase assay by use of radioactive galactose-1-phosphate. Clin. Chim. Acta, 10: 337 (1964).

11. PeNrose, I. S., AND Sirth, G. F.: Down's Anomaly. (Churchill, London, 1966).
12. Rondewald, M., AND WEBER, M.: Über den papierchromatographisch ermittelten Gehalt von Phosphor-Verbindungen in der säurelöslichen Fraktion des menschlichen Blutes I. Hoppe-Scyler's 7. Physiol. Chem., 306: 90 (1956).

13. RoInIFar.d, M., A.ND IVEBER, M.: Über den papierchromatographisch ermittelten Gchalt von Phosphor-Verbindungen in der säurelöslichen Fraktion des menschlichen Blutes II. Hoppe-Seyler's Z. Physiol. Chem., 311: 239 (1958).

14. Rosnfr, F., Ong, B. H., Paine, R. S., and Dershananand, M.: Biochemical differentiation of trisomic Down's syndrome (mongolism) from that due to translocation. New Fngl. J. Med., 273: 1356 (1965).

15. Rosnfr, I., ONg, B. H., P.ine, R. S., and Dershawanand, M.: Studies of blood enzymes in mongolism. J. Amer. Med. Ass., 19S: 328 (1966).

16. WrekNer, E.: Dex Gchalt an Adenosintriphosphat in Blut bei Kindern. Mschr. Kinderheilk. 108: 5 (1960).

17. International microcapillary centrifuge, model $\mathrm{MB}$, International Equipment Co., Needham Ireights, Mass.

18. Scrvall, Ivan Sorvall, Inc., Norwalk, Conn.

19. Requests for reprints should be addressed to: Józef Kf.uziona, M.D., Department of Biochemistry, Academy of Medicine, Lniversity of Lodz, ul. Emilii Plater $33 \mathrm{~m}$. 29, Lodty, Poland.

20. Accepted for publication March 29, 1971 . 